\title{
Prevalence of intimate partner violence against women and associated factors in Ethiopia
}

\author{
Ayele Gebeyehu Chernet ${ }^{*}$ (D) and Kebadu Tadesse Cherie
}

\begin{abstract}
Background: Violence against women is a major public health problem that affects the physical, sexual, mental, and social wellbeing of more than one third of all women globally. Violence against women in Ethiopia is widely acknowledged to be of great concern from human rights, economic and health perspective. The aim of this study was to assess the prevalence of intimate partner violence (IPV) against women and associated factors in Ethiopia.

Method: The data was obtained from 2016 Ethiopia Demographic and Health Survey which is the fourth survey conducted in Ethiopia as part of the worldwide project. The sample was selected using a stratified; two-stage cluster sampling design and the data was analyzed using logistic regression model.

Result: A total of 4714 ever-married women in reproductive age who reported their experience of spousal violence were considered from nine regional states and two city administratives. Over $30 \%$ of study participants were subjected to IPV. Living in rural areas, divorced, primary and secondary education, 25-39 years old, being poor are found to be predictors of IPV against women in Ethiopia.

Conclusion: The prevalence of IPV was found high in Ethiopia and government and any concerned bodies should design appropriate strategy and work hard to tackle the problem. There is a need of giving special attention for women living in rural area, women from poor family and 25-39 years old women to decrease the burden of IPV.
\end{abstract}

Keywords: Intimate partner violence, Prevalence, Logistic regression, Ethiopia

\section{Background}

Violence against women is a main public health problem that affects the physical, sexual, mental, and social wellbeing of more than one third of all women worldwide [1]. It is the deliberate and often repetitive physical, sexual, psychological, or economic abuse. The most common form of domestic violence is the ones committed in contradiction of women by their intimate partner $[2,3]$. Despite the Universal Declaration of the Human Rights, as all people begin to be recognized regardless of age, sex, race, color, language, religion, or any other factors, women have continued to suffer from domestic violence and discrimination in their homes [4].

Research conducted by WHO on domestic violence revealed that intimate partner violence (IPV) is the most

\footnotetext{
* Correspondence: gebeyehu29@gmail.com; ayele.gebeyehu@wku.edu.et Department of Statistics, College of Natural and Computational Sciences, Wolkite University, Wolkite, Ethiopia
}

common form of violence in women's lives and showed that women were at higher risk of violence at homes than in the streets and this has serious influences on women's health [5]. Sexually and physically abused women by intimate partners have a risk of 50 to $70 \%$ to be affected by gynecological, central nervous system, and stress related problems [6]. The World Bank has documented gender based violence as a heavy health problem for women aged 15 to 44 similar to the risk pretended by HIV, tuberculosis, infection during childbirth, cancer and heart disease [7].

IPV refers to behavior by an intimate partner that causes physical, sexual or psychological devastation, including actions of physical violence, sexual intimidation, and emotional abuse and controlling behaviors [8]. Many researches have verified a high prevalence of violence against women by intimate partners

(C) The Author(s). 2020 Open Access This article is distributed under the terms of the Creative Commons Attribution 4.0 International License (http://creativecommons.org/licenses/by/4.0/), which permits unrestricted use, distribution, and reproduction in any medium, provided you give appropriate credit to the original author(s) and the source, provide a link to the Creative Commons license, and indicate if changes were made. The Creative Commons Public Domain Dedication waiver (http://creativecommons.org/publicdomain/zero/1.0/) applies to the data made available in this article, unless otherwise stated. 
globally and the associated physical and mental health problems $[9,10]$.

According to multi-country study on women's health and domestic violence against women, the lifetime prevalence of physical, sexual, or both physical and sexual violence ranges from 15\% (Japan) to 71\% (Ethiopia). Nearly one half $(49 \%)$ of ever-married women faced physical violence, $59 \%$ of them experienced sexual violence, $71 \%$ of them had one or the other form of violence, or both, over their life time. About $35 \%$ of all ever-married women experienced at least one severe form of violence by a partner [11]. A cross sectional study conducted in Nigeria showed that almost one in four $(21.5 \%)$ ever-married women faced IPV at some point in their lives [12].

According to research conducted in Gonder referral Hospital, the overall prevalence of domestic violence among pregnant women was estimated to be $58.7 \%$ with emotional violence being the most common (57.8\%), followed by physical violence (32.2\%), and sexual violence (7.6\%). This research also showed that house wives, women with no salary of their own, partners' daily use of alcohol, and women who disobeyed their partner were found to be positively and significantly associated with domestic violence during pregnancy [13].

In Ethiopia, violence against women is widely acknowledged to be of great concern, not just from a human rights perspective, but also from an economic and health viewpoint. The government of Ethiopia reviewed its family law in 2000, its criminal law and constitution in 2005 , to protect and assurance the rights of women and children, and to promote gender equality and equity. IPV affects all the domains of women's lives such as selfesteem, productivity, autonomy, capacity to care for themselves and their children, ability to participate in social activities, and even death [11, 14]. Despite the international emphasis to reduce violence against women, the size of IPV is very high in Ethiopia. Thus, the aim of this study was to assess the prevalence of IPV against ever-married women and associated factors in Ethiopia.

\section{Methods}

\section{Source of data and study design}

The data was obtained from 2016 EDHS, which was taken from Central Statistical Agency (CSA). It is the fourth survey conducted in Ethiopia as part of the worldwide project. The 2016 EDHS sample was stratified and selected in two stages. Each region was stratified into urban and rural areas, yielding 21 sampling strata. Samples of Enumeration Areas (EAs) were selected independently in each stratum in two stages. Implicit stratification and proportional allocation were used at each of the lower administrative levels by sorting the sampling frame within each sampling stratum before sample selection, according to administrative units in different levels, and by using a probability proportional to size selection at the first stage of sampling.

In the first stage, a total of 645 EAs (202 EAs in urban areas and 443 EAs in rural areas) were selected with probability proportional to the EA size (based on the 2007 Population and House Census) and with independent selection in each sampling stratum. The resulting lists of households served as a sampling frame for the selection of households in the second stage. Some of the selected EAs were large, with more than 300 households. To minimize the task of household listing, each large EA selected for the 2016 EDHS was segmented. Only one segment was selected for the survey, with probability proportional to the segment size. Household listing was conducted only in the selected segment, that is, a 2016 EDHS cluster is either an EA or a segment of an EA.

In the second stage of selection, a fixed number of 28 households per cluster were selected with an equal probability systematic selection from the newly created household listing. Information was collected on IPV for ever-married women age 15-49 who reported their experience of spousal emotional, physical, and sexual violence. After excluding missing values, a total of 4714 ever-married women in reproductive age who reported their experience of spousal violence were considered in this study [15].

\section{Outcome variable}

The response variable was IPV where it combined all physical, sexual, and emotional form of violence. Series of independent questions were asked for each woman on physical, sexual and emotional violence. To identify physical violence, women were asked to confirm that whether their husband push, shake, or throw something; slap; twist arm or pull hair; punch with fist or with something else; kick, drag, or beat up; tried to choke or burn; threaten or attack with any material at them to deliberately hurt them at one point in lives. For identification of sexual violence women were asked whether their husband ever physically forced them to have sex or make other sexual acts when they do not want. Similarly, to derive emotional violence in the survey, women were asked whether their husband ever said or did something to disgrace them in the presence of others; threaten to hurt or harm them or someone close to them; or insulted or make them sense immoral about themselves [16]. In this study, indicators of specific type of spousal violence were combined to form two categories, namely women who had never experienced the specific violence, and women who had ever experienced at least one type of the specific violence. The three types of spousal violence were combined into a single spousal violence 
variable with binary outcomes of ever or never experienced at least one type of spousal violence.

\section{Explanatory variables}

Based on literature, Independent variables included in the analysis are described in Table 1 [12, 13, 17-26].

\section{Method of data analysis}

Based on the valid data obtained, we have performed a descriptive analysis using frequency and percentage for both dependent and independent variables. Binary logistic regression is typically used when the dependent variable is dichotomous and the independent variables are either continuous or categorical variables. One key assumption in binary logistic regression is that observations are independent of each other. Violations of the assumption of independence of observations may results in incorrect statistical inferences due to biased standard errors. After the model is fitted it is important to check how the model adequacy is, which can tell us the goodness of fit of the model. For this research we used Hosmer-Lemeshow test, which measures the correspondence between the actual and predicted values of the dependent variable [16].

Data cleaning, management and analysis were carried out using STATA, Version 12. Variables were re-coded to meet the desired classification. All hypotheses testing to determine differences, associations and relationships were judged significant at $p<0.05$.

\section{Inclusion exclusion criteria}

Only ever-married women in reproductive age who reported their experience of IPV were considered. Thus single/unmarried women and women who did not report their IPV experience were excluded.

\section{Result}

In this study a total of 4714 ever-married women in reproductive age who reported their experience of spousal violence were considered from nine regional states and two city administratives. According to the result presented in Table 2, most women lived in rural areas (74.3\%), but had a relatively low level of education; only $16.8 \%$ of women attended secondary and higher while half of them (49.0\%) of are uneducated. The sample has a fairly young age distribution and nearly two thirds of women $(71.3 \%)$ are married, while the rest of them are divorced and widowed. Over $30 \%$ of study participants were subjected to IPV. According to religion of respondents, the maximum burden of IPV is observed in other religions (37.9\%) while lowest (26.3\%) is observed among Muslim women.

About half of the divorced women $(43.6 \%)$ are victims of IPV while 26.5 and $28.7 \%$ of widowed and married women reported that they have experienced IPV respectively. The findings also showed that women who from rich and middle wealth categories are 31.2 and 30.7\% respectively which is less likely to experience IPV compared to women from poor wealth category (34.5\%).

Table 3 summarizes the prevalence of IPV among different regions of Ethiopia. The maximum IPV is found in Harari (39.1\%) followed by Oromia and Gambela regional states 38 and 35\% respectively while lowest (11.6\%) is observed in Somali regional state.

\section{Logistic regression model result}

Based on the result in Table 4, poor women had greater experience of IPV $(\mathrm{OR}=1.21$; $[0.92531 .4254])$ than rich women. According to place of residence, urban women have $34 \%$ less chance of experiencing IPV than rural women $(\mathrm{OR}=0.66 ; \mathrm{CI}=[0.5353,0.8127])$. The likelihood of experiencing IPV for divorced women is two times more likely than married women $(\mathrm{OR}=1.98$; $\mathrm{CI}$ : [1.6103, 2.4347]) while there is no significant difference between married and widowed women.

According to women's level of education, women having primary and secondary education level are 1.32 and 1.34 times more likely to experience IPV than uneducated women respectively while there is no significant difference between women having higher education and

Table 1 Description of Explanatory Variables used in the Analysis

\begin{tabular}{lll}
\hline Variable & Description & Category \\
\hline Age & Age of women & 15-19, 20-24, 25-29, 30-34, 35-39, 40-44, 45-49 \\
Marital status & Marital status of women & Married, Divorced, Widowed \\
Education & Education level of women & Uneducated, Primary, Secondary and Higher \\
Religion & Religion of women & Orthodox, Muslim, Protestant, Others \\
Wealth Index & Wealth index of the family & Poor, Middle, Rich \\
TV & Frequency of watching TV & Not at all, Sometimes, Always \\
Radio & Frequency of listening radio & Not at all, Sometimes, Always \\
Residence & women Place of residence & Rural, Urban \\
Region & Region of women & Tigray, Afar, Amhara, Oromia, Somali, Benishangul, SNNPR, Gambela, Harari, Addis Ababa, Dire Dawa \\
\hline
\end{tabular}


Table 2 Description of Status of IPV by basic covariates

\begin{tabular}{|c|c|c|c|c|c|}
\hline \multirow[t]{2}{*}{ Variable } & \multirow[t]{2}{*}{ Category } & \multirow[t]{2}{*}{ Total } & \multicolumn{2}{|c|}{ Domestic Violence } & \multirow[t]{2}{*}{$P$-value } \\
\hline & & & No & Yes & \\
\hline \multirow[t]{7}{*}{ Age } & $15-19$ & 1069(22.7\%) & 769(71.9\%) & $300(28.1 \%)$ & \\
\hline & $20-24$ & 915(19.4\%) & 638(69.7\%) & $277(30.3 \%)$ & \\
\hline & $25-29$ & $945(20.0 \%)$ & $648(68.6 \%)$ & 297(31.4\%) & \\
\hline & $30-34$ & $716(15.2 \%)$ & $502(70.1 \%)$ & 214(29.9\%) & 0.564 \\
\hline & $35-39$ & $507(10.8 \%)$ & $349(68.8 \%)$ & 158(31.2\%) & \\
\hline & $40-44$ & $323(6.9 \%)$ & $228(70.6 \%)$ & $95(29.4 \%)$ & \\
\hline & $45-59$ & $239(5.0 \%)$ & $165(69.0 \%)$ & 74(31.0\%) & \\
\hline \multirow[t]{4}{*}{ Religion } & Orthodox & 1778(37.7\%) & $1204(67.7 \%)$ & $574(32.3 \%)$ & \\
\hline & Protestant & 874(18.6\%) & $587(67.2 \%)$ & $287(32.8 \%)$ & \\
\hline & Muslin & 1973(41.9\%) & $1454(73.7 \%)$ & $519(26.3 \%)$ & $0.000^{* *}$ \\
\hline & Other & $87(1.8 \%)$ & $54(62.1 \%)$ & 33 (37.9\%) & \\
\hline \multirow[t]{2}{*}{ Residence } & Rural & $3503(74.3 \%)$ & $2422(69.1 \%)$ & $1081(30.9 \%)$ & $0.002^{* *}$ \\
\hline & Urban & $1211(25.7 \%)$ & 877 (72.4\%) & $334(27.6 \%)$ & \\
\hline \multirow[t]{4}{*}{ Education level } & Uneducated & 2309(49.0\%) & 1656(71.7\%) & $653(28.3 \%)$ & \\
\hline & Primary & $1613(34.2 \%)$ & 1099 (68.1\%) & $514(31.9 \%)$ & 0.082 \\
\hline & Secondary & $539(11.4 \%)$ & $368(68.3 \%)$ & $171(31.7 \%)$ & \\
\hline & Higher & $253(5.4 \%)$ & $176(69.6 \%)$ & $77(30.4 \%)$ & \\
\hline Wealth & Poor & 2108 & 1380 (65.5\%) & $728(34.5 \%)$ & \\
\hline \multirow[t]{2}{*}{ Index } & Middle & 666 & $458(68.8 \%)$ & $208(31.2 \%)$ & 0.026 \\
\hline & Rich & 1940 & 1344 (69.3\%) & $596(30.7 \%)$ & \\
\hline \multirow[t]{3}{*}{ Marital Status } & Married & 4117 & 2934(71.3\%) & 1183 (28.7\%) & \\
\hline & Divorced & 431 & $243(56.4 \%)$ & $188(43.6 \%)$ & $0.000^{* *}$ \\
\hline & Widowed & 166 & $122(73.5 \%)$ & 44 (26.5\%) & \\
\hline \multirow[t]{3}{*}{ Watching TV } & Not at all & 3367 & $2371(70.4 \%)$ & 996 (29.6\%) & \\
\hline & $\leq 1$ a week & 494 & $321(65.0 \%)$ & $173(35.0 \%)$ & $0.032^{* *}$ \\
\hline & $>1$ a week & 853 & $607(71.2 \%)$ & $246(28.8 \%)$ & \\
\hline \multirow[t]{3}{*}{ Listening Radio } & Not at all & 3301 & 2350 (71.2\%) & $951(28.8 \%)$ & \\
\hline & $\leq 1$ a week & 722 & 477 (66.1\%) & 245 (33.9\%) & $0.014^{* *}$ \\
\hline & $>1$ a week & 691 & $472(68.3 \%)$ & 219 (31.7\%) & \\
\hline Total & & 4714 & $3299(69.98 \%)$ & $1415(30.02 \%)$ & \\
\hline
\end{tabular}

uneducated women $(p$-value $=0.861)$. The odds of affected by IPV for women 25-29, 30-34, 35-39 years old are 1.32 (CI: [1.0752, 1.6150]), 1.30 (CI: [1.0409, 1.6337]), 1.36 (CI: 1.0616, 1.7418]) times more likely than women $15-19$ years old.

Hosmer and Lemeshow test (Table 5) revealed that $P$ value $=0.596$ indicating the model fits the data very well . This is good and implied that the model is indeed correctly specified.

\section{Discussion}

Women are vulnerable to violence from many different sources, but the WHO multi-country study on women's health and domestic violence against women of 2005 said that most violence against women is executed by an intimate partner [5]. The main goal of this study was to assess the prevalence of IPV against ever-married women and associated factors in Ethiopia. Accordingly, the result showed that nearly one in three ever-married women in Ethiopia (30.2\%) faced at least one type of IPV which indicates considerable number of women in the country is still suffering from it. These findings are consistent with a literature that shows IPV is common in Africa [5, 17].

The prevalence of IPV against women in this study is comparable with the result of other similar studies in Ivory Coast (32.1\%) [18], KwaZulu-Natal, Turkey (30.0\%) [27] and South Africa (31\%) [28]. This result 
Table 3 Summary of IPV by Regional States

\begin{tabular}{lllll}
\hline Religion & N & \multicolumn{2}{l}{ Domestic Violence } & \multirow{2}{*}{$\begin{array}{c}\text { - } \\
\text { value }\end{array}$} \\
\cline { 3 - 4 } & & No & Yes & \\
\hline Tigray & 502 & $343(68.3 \%)$ & $159(31.7 \%)$ & \\
Afar & 393 & $309(78.6 \%)$ & $84(21.4 \%)$ & \\
Ammhara & 569 & $388(68.2 \%)$ & $181(31.8 \%)$ & \\
Oromia & 648 & $402(62 \%)$ & $246(38 \%)$ & \\
Somali & 455 & $402(88.4 \%)$ & $53(11.6)$ & \\
Benishangul Gumuz & 388 & $257(66.2 \%)$ & $131(33.8 \%)$ & $0.000^{* *}$ \\
SNNPR & 558 & $391(70.1 \%)$ & $167(29.9 \%)$ & \\
Gambela & 337 & $219(65 \%)$ & $118(35 \%)$ & \\
Harari & 281 & $171(60.9 \%)$ & $110(39.1 \%)$ & \\
Addis Ababa & 294 & $213(72.4 \%)$ & $81(27.6 \%)$ & \\
Dire Dawa & 289 & $204(70.6 \%)$ & $85(29.4 \%)$ & \\
\hline
\end{tabular}

was also revealed that the prevalence of IPV is decreased by more than half from the finding of WHO multicountry study where the prevalence was $71 \%$. This difference may be due to the improvement made on IPV for the last 11 years in the Ethiopia. Furthermore, this multi-country study used a single rural setting from Ethiopia where intimate violence is estimated to be high.

In addition, the government is working hard on empowering female and avoiding dragging factors to increase political, social, and economical contribution of

Table 4 Result of Logistic Regression Model

\begin{tabular}{|c|c|c|c|c|}
\hline Variable & Category & OR & $95 \% \mathrm{Cl}$ for OR & $P$-Value \\
\hline \multirow[t]{3}{*}{ Wealth Index } & Rich & Ref & & \\
\hline & Middle & 1.04 & {$\left[\begin{array}{ll}0.86 & 1.26\end{array}\right]$} & 0.6890 \\
\hline & Poor & 1.21 & {$\left[\begin{array}{ll}1.07 & 1.43\end{array}\right]$} & $0.0325^{*}$ \\
\hline \multirow[t]{3}{*}{ Marital status } & Married & Ref. & & \\
\hline & Divorced & 1.98 & {$\left[\begin{array}{ll}1.61 & 2.43\end{array}\right]$} & $0.000^{*}$ \\
\hline & Widowed & 0.913 & [0.64 1.30] & 0.6150 \\
\hline \multirow[t]{3}{*}{ Place of residence } & Rural & Ref. & & \\
\hline & Urban & 0.66 & {$\left[\begin{array}{lll}0.54 & 0.81\end{array}\right]$} & $0.000^{*}$ \\
\hline & Uneducated & Ref. & & \\
\hline \multirow[t]{5}{*}{ Education level } & Primary & 1.32 & {$\left[\begin{array}{ll}1.12 & 1.55\end{array}\right]$} & $0.0010^{*}$ \\
\hline & Secondary & 1.34 & {$\left[\begin{array}{ll}1.05 & 1.70]\end{array}\right]$} & $0.0200^{*}$ \\
\hline & Higher & 1.20 & {$\left[\begin{array}{lll}0.86 & 1.65\end{array}\right]$} & 0.8610 \\
\hline & 15-19 & Ref. & & \\
\hline & $20-24$ & 1.19 & {$\left[\begin{array}{ll}0.97 & 1.45\end{array}\right]$} & 0.0940 \\
\hline \multirow[t]{5}{*}{ Age } & $25-29$ & 1.32 & {$\left[\begin{array}{ll}1.08 & 1.62\end{array}\right]$} & $0.0080^{*}$ \\
\hline & $30-34$ & 1.30 & {$\left[\begin{array}{lll}1.04 & 1.63\end{array}\right]$} & $0.0210^{*}$ \\
\hline & $35-39$ & 1.36 & {$\left[\begin{array}{ll}1.06 & 1.74\end{array}\right]$} & $0.0150^{*}$ \\
\hline & $40-44$ & 1.21 & {$\left[\begin{array}{ll}0.91 & 1.61\end{array}\right]$} & 0.2000 \\
\hline & $45-49$ & 1.38 & {$\left[\begin{array}{lll}0.10 & 1.90\end{array}\right]$} & 0.0510 \\
\hline
\end{tabular}

Table 5 Hosmer and Lemeshow Test

\begin{tabular}{lll}
\hline Chis-square & Df & Sig. \\
\hline 1.631 & 8 & 0.596 \\
\hline
\end{tabular}

women for their country. Moreover, the prevalence seen in this study was lower than those of studies conducted in countries such as Bolivia (47\%), Southern Sweden (39.5\%), Ghana (39\%), Portuguese (43.4\%), and Pakistan (51\%) [19, 29-32].

The study also revealed that divorced women are more likely to experience IPV than married women while there is no significant difference between married and widowed women. This high prevalence of IPV is expected to be the reason to be divorced. Similar results have been found in research conducted in Arkansas and New Mexico [21] and researchers also found that divorced Canadian women are four times more likely to be abused by a previous partner than married women [22].

The results of this study suggested that place of residences was significant predictive factor for IPV. Urban women have less chance of experiencing IPV than rural women. This higher prevalence rate of IPV on rural women may be due to the cultural perception, lack of knowledge and information in rural society where beating, insulting and other form of violence is considered as a means of shaping wife's behavior. Consistent results were also observed in other research such as in Nigeria [12], southeast Nigeria [20], they reported that rural women had greater chance of facing IPV. But findings from cross-sectional household surveys in eight southern African countries [17] showed that there is no significant difference on IPV among rural and urban women.

This study also showed that the likelihood of experiencing IPV increases with maternal education but there is no significant difference with women having higher education. This finding is consistent with research conducted in Nigeria [12]. But Contrary result was obtained in research conducted in Ivory Cost [18], Nigeria [12] where the likelihood of experiencing spousal violence reduces as maternal education improves. The study also revealed that women $25-39$ years old are more likely to experience IPV than 15-19 years old women. Similar result has been found in research conducted in eight southern African countries [17].

\section{Strength and limitation}

The primary strength of this study is that the analysis was based on the data collected from all regions of the country. Relatively large sample size respondents have been selected randomly and the data was collected by well-trained data collectors with strong supervision to maximize data quality. As limitation, this study used 
cross-sectional data that has limitation to determine causality. Furthermore, IPV is a sensitive subject that may be associated with negative feelings of guilt and stigma. Consequently, the women may have been reluctant to disclose their experiences of intimate partner violence, which may have affected the reported prevalence in this study. Thus, the findings of this study should be interpreted within this limitation.

\section{Conclusion}

Despite the fact that the government tried to lower violence against women, the prevalence of IPV among ever married women is high in Ethiopia. A total of 4714 ever married women in the reproductive age were considered in this study from which about $30 \%$ of them exposed to IPV. Based on these results, living in rural, being poor, being divorced and being 25-39 years old are found to be significant predictors of IPV. Hence, improving economic status of household and awareness creation for rural resident can be effective strategies to reduce IPV.

\section{Abbreviations}

Cl: Confidence interval; CSA: Central Statistical Agency; Df: Degree of freedom; EAs: Enumeration Areas; EDHS: Ethiopian Demographic and Health Survey; IPV: Intimate partner violence; OR: Odds Ratio; WHO: World Health Organization

\section{Acknowledgements}

The authors are grateful to CSA of Ethiopia for the data used in this study.

\section{Authors' contributions}

AG wrote the proposal and collected data from CSA. AG and KT performed the analysis, and wrote the manuscript. Both authors read and approved the final manuscript.

\section{Funding}

No funding was obtained for this study. Ethics approval and consent to participate

Ethics approval and participant consent were not necessary as this study involved the use of a previously-published database by CSA of Ethiopia.

\section{Availability of data and materials}

The dataset was demanded and retrieved from CSA website after formal online registration and submission of the project title and detail project description. The data can be accessed through http://www.statsethiopia.gov. et/.

\section{Consent for publication}

Not applicable.

\section{Competing interests}

The authors declare that they have no competing interests.

Received: 21 February 2019 Accepted: 27 January 2020

Published online: 07 February 2020

\section{References}

1. García-Moreno C, Pallitto C, Devries K, Stöckl H, Watts C, Abrahams N. Global and regional estimates of violence against women: prevalence and health effects of intimate partner violence and non-partner sexual violence. Geneva: World Health Organization; 2013.

2. World Health Organization. Dept. of Violence, Injury Prevention, World Health Organization. Violence, Injury Prevention, \& World Health Organization. Global status report on road safety: time for action. Geneva: World Health Organization; 2009.
3. World Bank Group. World development indicators 2014. Washington DC: World Bank Publications; 2014.

4. Declaration B. Platform for action. In: Fourth world conference on women, vol. 15; 1995. p. 2.

5. Krug EG, Mercy JA, Dahlberg LL, Zwi AB. The world report on violence and health. Lancet. 2002;360(9339):1083-8.

6. Garcia-Moreno C, Jansen HA, Ellsberg M, Heise L, Watts CH. Prevalence of intimate partner violence: findings from the WHO multi-country study on women's health and domestic violence. Lancet. 2006; 368(9543):1260-9.

7. Collymore Y. Conveying concerns: women report on gender-based violence; 2000.

8. World Health Organization. Responding to intimate partner violence and sexual violence against women: WHO clinical and policy guidelines. Geneva: World Health Organization; 2013.

9. Ellsberg $\mathrm{M}$, Jansen HA, Heise L, Watts $\mathrm{CH}$, Garcia-Moreno C. Intimate partner violence and women's physical and mental health in the WHO multicountry study on women's health and domestic violence: an observational study. Lancet. 2008;371(9619):1165-72.

10. Bott S, Guedes A, Goodwin MM, Mendoza JA. Violence against women in Latin America and the Caribbean: a comparative analysis of populationbased data from 12 countries; 2012

11. Garcia-Moreno C, Jansen HA, Ellsberg M, Heise L, Watts C. WHO multicountry study on women's health and domestic violence against women: initial results on prevalence, health outcomes and women's responses. Geneva: World Health Organization; 2005.

12. Benebo FO, Schumann B, Vaezghasemi M. Intimate partner violence against women in Nigeria: a multilevel study investigating the effect of women's status and community norms. BMC Womens Health. 2018;18(1):136

13. Fekadu E, Yigzaw G, Gelaye KA, Ayele TA, Minwuye T, Geneta T, Teshome DF. Prevalence of domestic violence and associated factors among pregnant women attending antenatal care service at University of Gondar Referral Hospital, Northwest Ethiopia. BMC Womens Health. 2018;18(1):138

14. Pourasadi M, Hashemi M. Phenomenon of divorce and custody of children after separation; 2012.

15. Central Statistical Agency (CSA) Ethiopia and ICF. Demographic and Health Survey 2016: Key Indicators Report. Addis Ababa, Rockville: CSA and ICF: 2016.

16. Agresti A. Categorical Data Analysiss. Second Edition, Wiley In., Publication. Gainesville: University of Florida; 2002.

17. Andersson N, Ho-Foster A, Mitchell S, Scheepers E, Goldstein S. Risk factors for domestic physical violence: national cross-sectional household surveys in eight southern African countries. BMC Womens Health. 2007;7(1):11

18. Peltzer K, Pengpid S. Female genital mutilation and intimate partner violence in the Ivory Coast. BMC Womens Health. 2014;14(1):13.

19. Meekers D, Pallin SC, Hutchinson P. Intimate partner violence and mental health in Bolivia. BMC Womens Health. 2013;13(1):28.

20. Ajah LO, lyoke CA, Nkwo PO, Nwakoby B, Ezeonu P. Comparison of domestic violence against women in urban versus rural areas of Southeast Nigeria. Int J Women's Health. 2014;6:865.

21. Shobe M, Christy K, Givens A, Hamilton L, Jordan S, Murphy-Erby Y. Cohabitation and marital status: their relationship with economic resources and intimate partner violence. Int J Humanit. 2011;9:2.

22. Brownridge DA, Chan KL, Hiebert-Murphy D, Ristock J, Tiwari A, Leung W-C, Santos SC. The elevated risk for non-lethal post-separation violence in Canada: A comparison of separated, divorced, and married women. J Interpers Violence. 2008;23(1):117-35.

23. Al-Atrushi HH, Al-Tawil NG, Shabila NP, Al-Hadithi TS. Intimate partner violence against women in the Erbil city of the Kurdistan region, Iraq. BMC Womens Health. 2013;13(1):37

24. Makayoto LA, Omolo J, Kamweya AM, Harder VS, Mutai J. Prevalence and associated factors of intimate partner violence among pregnant women attending Kisumu District hospital, Kenya. Matern Child Health J. 2013;17(3): $441-7$.

25. Okada MM, Hoga LAK, Borges ALV, Albuquerque RSD, Belli MA. Domestic violence against pregnant women. Acta Paulista de Enfermagem. 2015. 28(3):270-4

26. Perales MT, Cripe SM, Lam N, Sanchez SE, Sanchez E, Williams MA Prevalence, types, and pattern of intimate partner violence among pregnant women in Lima, Peru. Violence Against Women. 2009;15(2): 224-50. 
27. Sen S, Bolsoy N. Violence against women: prevalence and risk factors in Turkish sample. BMC Womens Health. 2017;17(1):100.

28. Hoque ME, Hoque M, Kader SB. Prevalence and experience of domestic violence among rural pregnant women in KwaZulu-Natal, South Africa. Southern African J Epidemiol Infect. 2009;24(4):34-7.

29. Finnbogadóttir H, Dykes AK, Wann-Hansson C. Prevalence of domestic violence during pregnancy and related risk factors: a cross-sectional study in southern Sweden. BMC Womens Health. 2014;14(1):63.

30. Doku DT, Asante KO. Women's approval of domestic physical violence against wives: analysis of the Ghana demographic and health survey. BMC Womens Health. 2015;15(1):120.

31. Coutinho E, Almeida F, Duarte J, Chaves C, Nelas P, Amaral O. Factors related to domestic violence in pregnant women. Procedia Soc Behav Sci. 2015;171:1280-7.

32. Karmaliani R, Iran F, Bann CM, McClure EM, Moss N, Pasha O, Goldenberg RL. Domestic violence prior to and during pregnancy among Pakistani women. Acta Obstet Gynecol Scand. 2008;87(11):1194-201.

\section{Publisher's Note}

Springer Nature remains neutral with regard to jurisdictional claims in published maps and institutional affiliations.

Ready to submit your research? Choose BMC and benefit from:

- fast, convenient online submission

- thorough peer review by experienced researchers in your field

- rapid publication on acceptance

- support for research data, including large and complex data types

- gold Open Access which fosters wider collaboration and increased citations

- maximum visibility for your research: over $100 \mathrm{M}$ website views per year

At $\mathrm{BMC}$, research is always in progress.

Learn more biomedcentral.com/submissions 